\title{
Pembuatan minyak plastik dengan proses pirolisis
}

\author{
Ch. Rangkuti ${ }^{1}$, Tono Sukarnoto ${ }^{2}$ M. Rijani²
}

${ }^{1}$ Jurusan Teknik Mesin, Fakultas Teknologi Industri, Universitas Trisakti Email korespondensi: tsukarnoto@trisakti.ac.id

\begin{abstract}
Abstrak
Pada saat ini khususnya di kota besar seperti Jakarta tentunya banyak sekali kebutuhan masyarakat akan berbagai komoditas setiap harinya. Begitu pula dengan jumlah sampah yang dihasilkan setiap harinya mencapai \pm 6000 ton yang dibuang ke TPU Bantar Gebang, dan diantara dari sampah tersebut 13\%-14\% adalah berjenis plastik, belum lagi yang tidak terpungut oleh pemulung. Ada baiknya sampah ini dimanfaatkan menjadi suatu yang berguna dibanding dengan kebiasaan masyarakat yang sering membakar sampah. Pembakaran sampah akan membuat polusi udara apalagi jika sampah plastik. Dalam penelitian ini dibuat bahan bakar minyak yang bersumber dari plastik dengan menggunakan metode gasifikasi dan destilasi yang akan mengubah gas dari plastik tersebut menjadi minyak. Dari hasil penelitian ini didapatkan bahwa minyak plastik yang dihasilkan adalah mendekati unsur minyak solar. Jumlah minyak yang dihasilkan dari setiap kg bahan baku plastik dihasilkan 570 ml minyak plastik. Minyak ini adalah mendekati jenis minyak solar.
\end{abstract}

Kata kunci: plastik, pirolisis, kondensor, prosessor pemanas

\begin{abstract}
Especially at this time in big cities like jakarta is certainly a lot of society for various commodities every day Similarly, the amount of waste generated every day reaches \pm 6000 tons which is dumped into bantar gebang tpu, and among of the waste $13 \%-14 \%$ is plastic type, not to mention not picked up by scavengers.It is better to use this waste to be a useful compared to the habits of people who as often as burn garbage.Burning waste will make water pollution especially if plastic waste. In this study made fuel oil sourced from plastic using gasification and distillation method that will convert gas from plastic into oil .From the results of this study found that the resulting plastic oil is close to the an element of of diesel oil .The amount of oil produced from each $\mathrm{kg}$ of plastic raw material produced $570 \mathrm{ml}$ of plastic oil .This oil is close to the type of diesel oil..
\end{abstract}

Keywords: plastic, pyrolysis, condenser, processor heater

\section{Pendahuluan}

Pada jaman yang semakin berkembang, hampir disemua Negara mempunyai masalah yang sama, yaitu sampah. Apalagi di Indonesia kebutuhan akan bahan bakar dan juga makanan cepat saji menjadi prioritas seluruh kalangan. Peningkatan sampah kota di Jakarta merupakan dampak dari perkembangan kota. Hasil dari pembakaran fosil dan juga banyak sampah yang tidak bisa terurai adalah masalah yang terus semakin membesar tanpa ada solusi dan juga banyaknya masyarakat yang kurang peduli dengan lingkungan. Peningkatan penggunaan plastik untuk keperluan rumah tangga berdampak pada peningkatan timbunan sampah plastik. Sehingga perlu dilakukan usaha untuk membuat bahan bakar alternatif dari sampah plastik yang diharapkan bisa dipakai secara luas bagi masyarakat.

Saat ini jumlah sampah tiap harinya yang masuk di TPA Bantar Gebang sekitar 6.000 ton dan sekitar 13\% - 14\% merupakan sampah plastik [5]. Di tambah lagi dengan sampah plastik yang tidak terpungut oleh pemulung. Banyak masyarakat yang mengabaikan saja dan ada juga memusnahkan dengan cara dibakar.
Padahal cara seperti itu merupakan cara yang sangat tidak baik dan merusak lingkungan.

Perlu adanya proses daur ulang yang lebih baik terhadap sampah plastik tersebut. Salah satunya dengan mengkonversi sampah plastik menjadi minyak, mengingat bahwa plastik berasal dari minyak bumi. Selain itu plastik mempunyai nilai kalor yang cukup tinggi yang setara dengan bahan bakar fosil seperti bensin dan solar.

Beberapa penelitian seputar konversi sampah plastik menjadi produk cair berupa bahan bakar telah dilakukan dan menunjukkan hasil yang cukup prospektif untuk dikembangkan [3]. Perlu dicari datadata tentang jenis plastik tersebut dan juga proses pengolahannya yang baik agar produksi minyak dari sampah plastik tersebut lebih optimum.

\section{Metode}

\section{Pirolisis dan destilasi}

Pirolisis adalah dekomposisi kimia bahan organik melalui proses pemanasan tanpa atau sedikit oksigen atau reagen lainnya, di mana material mentah akan mengalami pemecahan struktur kimia 
menjadi fase gas. Pirolisis adalah kasus khusus termolisis. Pirolisis ekstrem, yang hanya meninggalkan karbon sebagai residu, disebut karbonisasi.

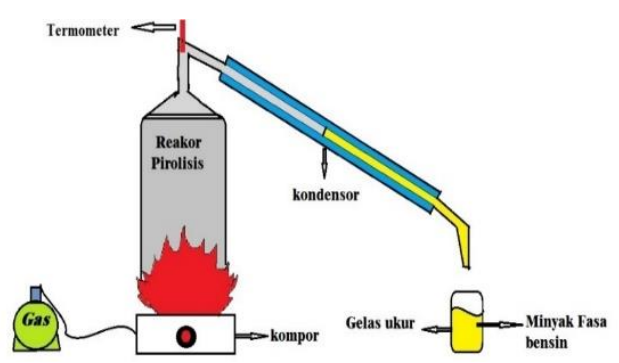

Gambar 1. Proses pirolisis dan destilasi sederhana

Metode pirolisis termasuk distilasi atau penyulingan adalah suatu metode pemisahan bahan kimia berdasarkan perbedaan kecepatan atau kemudahan menguap (volatilitas) bahan.

Dalam penyulingan, campuran zat dipanaskan dan diubah menjadi gas, dan gas ini kemudian didinginkan hingga gas tadi berubah kembali ke dalam bentuk cairan. Zat yang memiliki titik didih lebih rendah akan berubah menjadi gas lebih dulu sesuai dengan titik didihnya.

Berikut ini adalah skematika dan urutan peralatan yang digunakan.

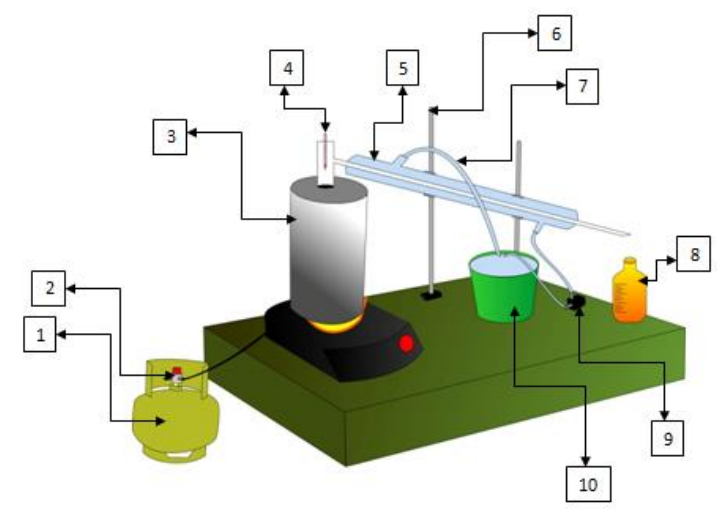

Gambar 2: Skema Alat Kerja Keterangan Gambar

1. Gas LPG

2. Regulator Gas

3. Reaktor Pirolisis

4. Termometer

5. Kondensor

6. Selang kondensor

7. Tiang penyangga kondensor

8. Botol Pengukur

9. Pompa Aquarium

10. Penampung Air

\section{Memulai proses kerja}

Pertama, masukan potongan plastik seberat $1 \mathrm{~kg}$ kedalam reaktor, lalu panaskan hingga plastik meleleh dan berubah jadi gas seluruhnya. Atur panas api agar gas dapat naik dengan menjaga suhu gas sesuai parameter yang di tetapkan sebelum masuk ke kondensor. Setelah masuk dalam kondensor disinilah terjadi proses destilasi yang akan merubah plastik fasa gas menjadi cair dan pada akhirnya di tampung pada gelas kaca. Setelah itu di saring menggunakan kertas saring serta pisahkan air dengan minyak.

Setelah minyak dari bahan baku plastik tersebut selesai di buat, selanjutnya minyak ini akan di lakukan proses penyaringan dan uji laboratorium.

Minyak dari hasil destilasi ini tentunya masih mengandung kotoran yang menyebabkan warna dari minyak tersebut keruh. Untuk itu digunakan kertas saring untuk memisahkan kotoran yang ada pada minyak tersebut.

Pengujian karakteristik terhadap minyak destilasi dilakukan pada sampel minyak tersebut. Dari sinilah bisa diketahui apakah minyak yang dihasilkan berupa unsur solar atau bensin berdasarkan suhu penguapannya.

Bahan bakar yang dihasilkan dari proses kondensasi masih keruh, dan masih banyak terdapat kotoran yang ikut terbawa saat proses gasifikasi. Kotoran yang terdapat berupa plastik kental yang berwarna putih susu.

Penyebab minyak yang dihasilkan menjadi keruh kemungkinan disebabkan oleh:

Adanya proses gasifikasi pertama bersamaan dengan kandungan air yang terdapat pada bahan baku plastik. sehingga dapat terlihat perbedaan air dan minyak secara jelas. Yang kedua karena bahan plastik yang menguap dan pada saat di kondensasikan mempunyai fisik kenyal pada dasarnya. Sehingga terlihatlah gumpalan/jel berwarna putih seperti ditunjukkan dalam gambar berikut:

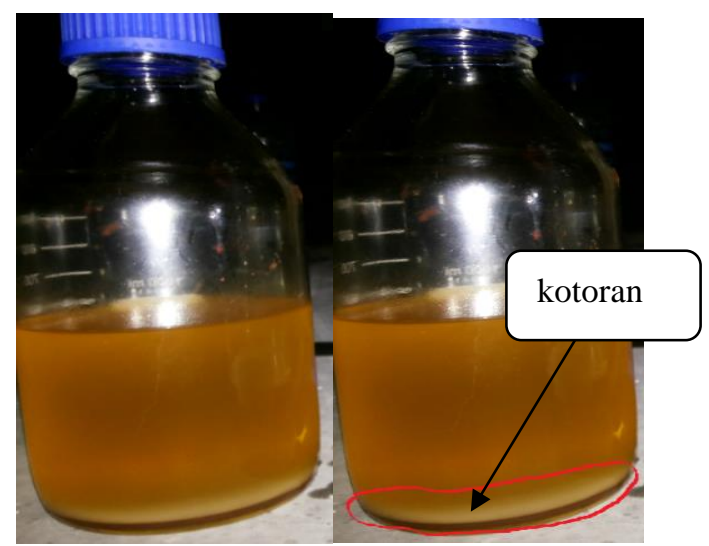

(a)

(b)

Gambar 3. (a) minyak hasil dari bahan baku plastik (b) kotoran yang ada pada minyak tersebut. 
Langkah selanjutnya adalah membiarkan minyak dari plastik ini di dalam ruang yang cukup dingin. Yang bertujuan agar kotoran pada minyak tersebut akan menggumpal di dasar botol. Setelah minyak tersebut disaring dengan kertas saring maka hasilnya minyak tidak keruh lagi, menjadi minyak bersih seperti ditunjukkan dalam gambar berikut.

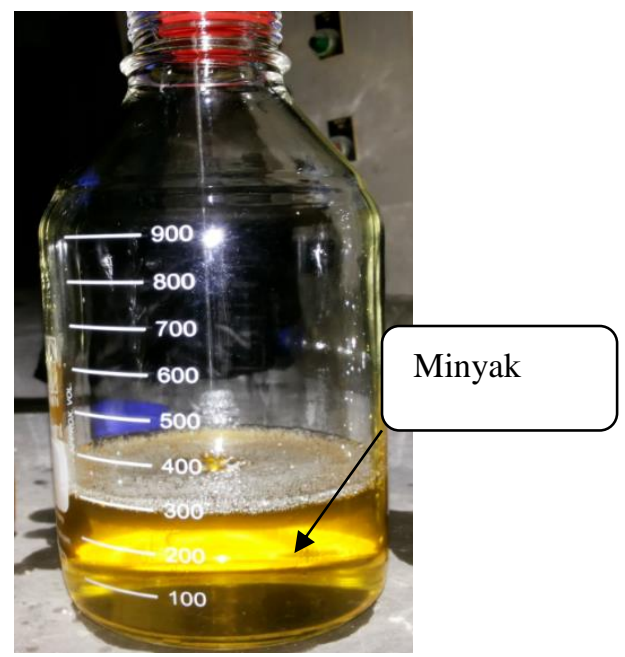

Gambar 4. Minyak yang sudah di saring

Dari percobaan yang dilakukan, dari 1 (satu) $\mathrm{kg}$ plastik yang dimasukkan kedalam proses menghasilkan minyak plastik sebanyak $570 \mathrm{~mL}$.

\section{Hasil dan Pembahasan}

\section{Uji Laboratorium Bahan Bakar}

Setelah disaring, sampel di bawa ke laboratorium untuk dilakukan tes destilasi karakteristik. Dari tes ini dapat diketahui karakteristik minyak yang dihasilkan Apakah dalam karakteristik minyak bensin atau minyak solar berdasarkan suhu penguapannya. Pengujian destilasi karakteristik ini mengacu pada standar ASTM D 68-12 yang merupakan metode standar untuk destilasi minyak dengan tekanan atmosfer. Sudah diketahui bahwa karakteristik didih bensin $40-150{ }^{\circ} \mathrm{C}$, sedangkan solar $180-340{ }^{\circ} \mathrm{C}$

Hasil pengujian dari sampel tersebut adalah sebagai berikut:

Tabel 1. Hasil Destilasi Karakteristik Sampel Minyak Plastik

\begin{tabular}{cc}
\hline $\begin{array}{c}\text { Volume } \\
(\%)\end{array}$ & $\begin{array}{c}\text { Suhu } \\
\left({ }^{\circ} \mathrm{C}\right)\end{array}$ \\
\hline 5 & 136 \\
10 & 140 \\
20 & 149 \\
30 & 158 \\
40 & 171 \\
50 & 191 \\
60 & 220 \\
\hline
\end{tabular}

\begin{tabular}{ll}
\hline 70 & 241 \\
80 & 260 \\
90 & 291 \\
95 & 322 \\
\hline
\end{tabular}

Dari Tabel 1, dapat dilihat volume bahan-bakar yang menguap berdasarkan temperatur bahan-bakar saat dipanaskan. Dari sini dapat diketahui berapa jumlah persentase minyak dengan unsur minyak bensin dan diesel berdasarkan titik penguapannya.

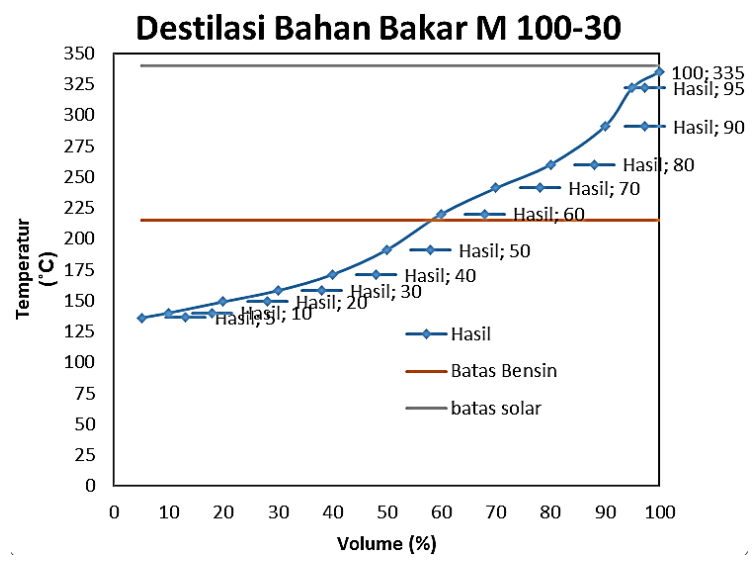

Gambar 5. Grafik Destilasi Sampel

Dari grafik di atas terlihat sekitar $20 \%$ dari volume destilasi tersebut berkarakter minyak bensin dan $80 \%$ berkarakter minyak solar. Maka dapat dikatakan bahwa minyak plastik yang dihasilkan adalah lebih berkarakteristik minyak solar.

Dari hasil pengujian sampel sebanyak $50 \mathrm{ml}$ di laboratorium Massa didapatkan hasil yang menunjukan bahwa $69 \%$ pada minyak tersebut mengandung ikatan karbon dari rentang 13-20 yang mana ini menunjukkan bahwa minyak plastik tersebut adalah lebih bersifat minyak solar.

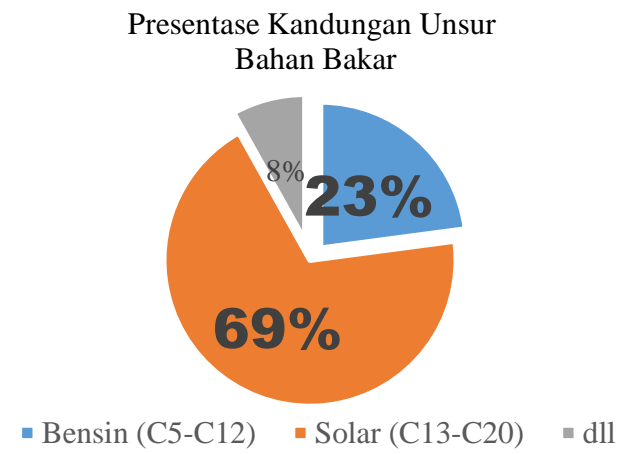

Gambar 6. Presentase kandungan karbon yang ada pada minyak tersebut.

Dari percobaan yang dilakukan, biaya yang dibutuhkan untuk pembuatan minyak plastik ini terdiri dari harga limbah plastik yang digunakan sebagai bahan baku serta harga gas LPG yang digunakan untuk memanaskan reaktor pirolisis adalah berkisar Rp. 4000,- per kg limbah plastik yang digunakan. 


\section{Kesimpulan}

Dengan suhu gas plastik $100{ }^{\circ} \mathrm{C}$ yang masuk ke dalam kondensor dapat menghasilkan $570 \mathrm{~mL}$ minyak dari $1 \mathrm{~kg}$ plastik yang diolah. Minyak yang dihasilkan dari limbah plastik ini lebih mendekati karakteristik minyak solar. Biaya yang dibutuhkan untuk pembuatan minyak plastik ini terdiri dari harga limbah plastik yang digunakan sebagai bahan baku serta harga gas LPG yang digunakan untuk memanaskan raektor pirolisis adalah berkisar $\mathrm{Rp}$. 4000,- per kg limbah plastik yang digunakan.

\section{Daftar Pustaka}

[1] Wartawan, Aton L1997. Bahan Bakar Bensin Otomotif: Penerbit Trisakti, Jakarta.

[2] Ramadhan,Eprian dan Munawar.,2011, Pengolahan Sampah Plastik Menjadi Minyak Menggunakan Proses Pirolisis, Jurnal Ilmiah Teknik Lingkungan, Vol. 4 No. 1.

[3] Mustofa, D. 2014, Pirolisis Sampah Plastik Hingga Suhu $900^{\circ} \mathrm{C}$ Sebagai Upaya Menghasilkan Bahan Bakar Ramah Lingkungan.Simposium Nasional RAPI XIII2014.ISSN1412-9612,

[4] Natalia, M. 2013, Pengolahan Sampah Organik (Sayur-Sayuran).Seminar Nasional Mesin Usakti, , Jakarta.

[5] Migristine,Rinrin. 2009. Pengolahan Sampah Plastik. Titian Ilmu . Jakarta

[6] Budi,Untoro S. 2013, Berbagai Metode Sampah Plastik Menjadi Bahan Bakar Minyak, Jurnal Teknik vol.3 no.1. 2013.

[7] http://www.ampl.or.id/digilib/read/46mengkhawatirkan-sampah-plastik-capai-5-4juta-ton-per-tahun/49539

[8] https://id.wikipedia.org/wiki/Bahan_bakar 